\title{
An Alternate Proof of Mason's Theorem
}

\author{
Noah Snyder \\ Noah Snyder is an undergraduate student at Harvard University. He plans on contin- \\ uing in mathematics in both graduate school and as a career. At present he is most \\ interested in Number Theory. He also plays on Harvard's Ultimate Frisbee team. He \\ loves theatre, the band REM, and Douglas Adam's "The Hitchhiker's Guide to the \\ Galaxy".
}

Definition. Let $f$ be a non-zero polynomial in $k[x]$ for some algebraically closed field $k$. We define $n_{0}(f)$ to be the number of distinct zeroes of $f$.

Lemma. Let $f$ be a non-zero polynomial in $k[x]$. Then,

$$
\operatorname{deg}(f) \leq \operatorname{deg}\left(f, f^{\prime}\right)+n_{0}(f)
$$

where $(g, h)$ denotes the greatest common divisor $(g c d)$ of $g, h$.

Remark 1. Since the derivative is a purely algebraic operation of polynomials, it makes sense to talk about the derivative in $k[x]$. Furthermore, all the familiar rules of calculus can be proven algebraically in this new context.

In dem folgenden Beitrag von N. Snyder kommen wir auf den Elemente-Aufsatz von S. Lang über die $a b c$-Vermutung aus dem Jahr 1993 zurück (siehe El. Math. 48 (1993), 89-99). Dort wurde der von R.C. Mason gefundene Beweis der $a b c$-Vermutung für Polynome vorgestellt. In der Zwischenzeit hat N. Snyder, ein junger Mathematik-Student, einen noch wesentlich einfacheren Beweis des Satzes von Mason gefunden, den wir hier wiedergeben. Anhand dieses Beispiels kann sehr schön verfolgt werden, wie sich im Laufe der Zeit Beweise von Sätzen vereinfachen, ein wichtiges Element für die Entwicklung der Mathematik. Die (jungen) Leserinnen und Leser mögen durch diesen Beitrag von N. Snyder angespornt werden, nach solch' überraschenden Lösungen zu suchen. $j k$ 
Proof of the lemma. Let $\alpha_{1}, \ldots, \alpha_{m}$ be the roots of $f$ with multiplicities $a_{1}, \ldots, a_{m}$, so that $f=c\left(x-\alpha_{1}\right)^{a_{1}} \cdot \ldots \cdot\left(x-\alpha_{m}\right)^{a_{m}}$. Then, by the product rule,

$$
\begin{aligned}
f^{\prime}= & c a_{1}\left(x-\alpha_{1}\right)^{a_{1}-1}\left(x-\alpha_{2}\right)^{a_{2}} \cdot \ldots \cdot\left(x-\alpha_{m}\right)^{a_{m}} \\
& +c\left(x-\alpha_{1}\right)^{a_{1}} \frac{d}{d x}\left(\left(x-\alpha_{2}\right)^{a_{2}} \cdot \ldots \cdot\left(x-\alpha_{m}\right)^{a_{m}}\right) .
\end{aligned}
$$

Therefore, $\left(x-\alpha_{1}\right)^{a_{1}-1} \mid\left(f, f^{\prime}\right)$. Similarly, $\left(x-\alpha_{i}\right)^{a_{i}-1} \mid\left(f, f^{\prime}\right)$. So we see that $\left(x-\alpha_{1}\right)^{a_{1}-1}$. $\ldots \cdot\left(x-\alpha_{m}\right)^{a_{m}-1} \mid\left(f, f^{\prime}\right)$. Therefore, since $f$ is non-zero, $\operatorname{deg}(f)-n_{0}(f) \leq \operatorname{deg}\left(f, f^{\prime}\right)$. The lemma follows immediately.

Remark 2. If $k$ is of characteristic zero then, in the statement of the lemma, equality holds. The following theorem, however, requires only this weaker lemma.

Theorem (Mason's Theorem). Let $a, b$, and $c$ be relatively prime polynomials in $k[x]$ such that $a+b=c$. Furthermore, we require that $a^{\prime}, b^{\prime}$, and $c^{\prime}$ are not all zero. Then, $\operatorname{deg}(c) \leq n_{0}(a b c)-1$.

Proof. $a+b=c$. Therefore, $a^{\prime}+b^{\prime}=c^{\prime}$. Multiplying the first equation by $a^{\prime}$, the second by $a$, and subtracting, we find that $a^{\prime} b-a b^{\prime}=a^{\prime} c-a c^{\prime}$. Therefore, $\left(a, a^{\prime}\right),\left(b, b^{\prime}\right)$, and $\left(c, c^{\prime}\right)$ all divide $a^{\prime} b-a b^{\prime}$. Since they are relatively prime,

$$
\left(a, a^{\prime}\right)\left(b, b^{\prime}\right)\left(c, c^{\prime}\right) \mid\left(a^{\prime} b-a b^{\prime}\right)
$$

I claim that the right hand side is non-zero. If $a^{\prime} b-a b^{\prime}=0$, then $a \mid a^{\prime} b$. Since $a$ and $b$ are relatively prime, $a \mid a^{\prime}$. Therefore, $a^{\prime}=0$. Similarly, $b^{\prime}$ and $c^{\prime}$ would also be zero, contradicting the assumption. Therefore, the right hand side is non-zero, and

$$
\operatorname{deg}\left(a, a^{\prime}\right)+\operatorname{deg}\left(b, b^{\prime}\right)+\operatorname{deg}\left(c, c^{\prime}\right) \leq \operatorname{deg}(a)+\operatorname{deg}(b)-1 .
$$

We move everything to the right hand side and $\operatorname{add} \operatorname{deg}(c)$ to both sides to find that

$$
\operatorname{deg}(c) \leq \operatorname{deg}(a)-\operatorname{deg}\left(a, a^{\prime}\right)+\operatorname{deg}(b)-\operatorname{deg}\left(b, b^{\prime}\right)+\operatorname{deg}(c)-\operatorname{deg}\left(c, c^{\prime}\right)-1 .
$$

Applying the lemma yields the required result.

Remark 3. If $k$ is of characteristic zero, then $f^{\prime}$ being non-zero is equivalent to $f$ being non-constant, and so we get the familiar statement of Mason's Theorem.

Noah Snyder

Harvard University

417 Adams Mail Center

Cambridge, MA 02138, U.S.A.

e-mail: nsnyder@fas.harvard.edu 